\title{
Atividade inibitória das folhas e caule de Kalanchoe brasiliensis Cambess frente a microrganismos com diferentes perfis de resistência a antibióticos
}

\author{
Jackeline G. da Silva, ,', Maria do Socorro V. Pereira, ${ }^{2}$ Ana Pavla Diniz, Gurgel, ${ }^{1}$ \\ José Pinto de Siqueira-Júnior, ${ }^{2}$ Ivone A. de Souza ${ }^{1}$
}

\author{
${ }^{1}$ Universidade Federal de Pernambuco, Departamento de Antibióticos, Av. Arthur de Sá s/n. Cidade Universitária, \\ 50740-521 Recife-PE, Brasil \\ ${ }^{2}$ Universidade Federal da Paraíba, Departamento de Biologia Molecular, Av. Contorno da Cidade Universitária s/n, \\ Cidade Universitária, 58059-900- João Pessoa-PB, Brasil
}

\begin{abstract}
RESUMO: A avaliação antimicrobiana das partes aéreas de Kalanchoe brasiliensis Cambess, Crassulaceae, a qual é comumente utilizada para o tratamento de inflamações da mucosa oral, bronquites e congestão nasal, é relatada. Esta atividade foi avaliada em discos de Petri usando o método de difusão para a determinação da Concentração Inibitória Mínima (MIC) e cinética bactericida. Foram usadas amostras bacterianas gram-positivas, gram-negativas e cepas de fungos leveduriformes do gênero Cândida. Apenas o óleo essencial demonstrou ser efetivo, apresentando atividade frente amostras gram-positivas de Staphylococcus aureus (MRSA) meticilina resistente. A ação observada foi considerada bacteriostática por reduzir um $\log _{10} \mathrm{UFC} / \mathrm{mL}$ a partir da sexta hora de exposição da amostra ao óleo essencial nas concentrações de 4\% e 8\%. Compostos fenólicos estão presentes em óleo essencial, sugerindo que o efeito foi devido à presença dos mesmos. Por este motivo à planta Kalanchoe brasiliensis Cambess pode representar uma alternativa terapêtica para infecções provocadas por Staphylococcus aureus.
\end{abstract}

Unitermos: Antimicrobiano, Kalanchoe brasiliensis, Crassulaceae, Staphylococcus aureus.

\begin{abstract}
Inhibitory activity of aerial parts of Kalanchoe brasiliensis Cambess against microorganisms with variation profile antibiotic-resistant". This study reports the antimicrobial evaluation of the aerial parts of Kalanchoe brasiliensis Cambess, Crassulaceae, commonly used for the treatment of the oral mucosa inflammation, bronchitis and nasal congestion. The antimicrobial activity was assayed in petri dishes using the diffusion method for determination of the minimal inhibitory concentration (MIC) and the kill curve kinetic methods. It were used gram-positive and gram-negative strain, leveduriforms fungi strain classified in genus Cândida. Only the essential oil showed activity against methicilin resistant Staphylococcus aureus (MRSA). This action was considered bacteriostatic with the reduction to one $\log _{10} \mathrm{CFU} / \mathrm{ml}$ after six hour of exhibition at the concentration of $4 \%$ and $8 \%$. There are studies accounts that polyphenols are present in the essential oil and are active against bacteria. K. brasiliensis is rich in polyphenols suggering that the antimicrobial effect showed is due to this. For this reason, the plant Kalanchoe brasiliensis, can represent a therapeutic alternative against infections caused for Staphylococcus aureus.
\end{abstract}

Keywords: Antimicrobial activity, Kalanchoe brasiliensis, Crassulaceae, Staphylococcus aureus.

\section{INTRODUÇÃO}

A terapia antimicrobiana contra Staphylococcus aureus tem se tornado um grande problema no tocante a infecções hospitalares, devido à freqüente resistência adquirida por esse patógeno, desde a descoberta das penicilinas e, em seguida, aos beta-lactâmicos. A aquisição desses genes de resistência é facilitada pelo o uso abusivo de drogas antimicrobianas, e disseminados via plasmídio de resistência presentes em cepas de S. aureus, como descrito por Stratton (2000). O problema torna-se mais preocupante, porque $S$. aureus tem a capacidade de desenvolver múltiplos mecanismos de resistência como: bomba de efluxo, inativação de aminoglicosídios e modificação nas PBPs - Proteínas ligadoras de penicilinas e uma alteração de extrema importância em PBP-2, que confere resistência a todos os beta-lactâmicos originando cepas chamadas de $S$. aureus meticilina resistente (MRSA) (Ito et al., 2003).

Por um longo período de tempo as plantas 
têm sido utilizadas como fonte de produtos naturais em combate a várias enfermidades, e isso tem sido cada vez mais aceito aqui no Brasil, segundo a (OMS) Organização Mundial de Saúde (Veiga Jr. et al., 2005). A busca de plantas com atividade antimicrobiana tem aumentado nas últimas décadas em muitos países, devido a sua riqueza de constituintes, a exemplo, os compostos fenólicos como os flavonóides os quais possuem potente ação antibacteriana (Cowan, 1999; Nascimento et al., 2000).

A planta Kalanchoe brasiliensis Cambess, Crassulaceae, conhecida no nordeste brasileiro como saião e coirama-branca, tem um amplo uso na região para o tratamento de feridas, abscessos, furúnculos e infecções genito-urinárias (Cunha et al., 1995). Outros estudos demonstram ações farmacológicas como antiinflamatória, imunomoduladora, larvicida e anticolinesterásica (Mourão et al., 1999; Costa et al., 2006; Ibrahim et al., 2002; Trevisan et al., 2006). Uma variedade de constituintes já foi revelada em $K$. brasiliensis como flavonóides glicosilados e esteróides (Trevisan et al., 2006; Costa et al., 1994).

O presente trabalho tem por objetivo avaliar a atividade antimicrobiana das partes aéreas (folhas e caule) de Kalanchoe brasiliensis frente a amostras bacterianas gram-positivas e gram-negativas resistentes e sensíveis a antibióticos e em amostras de fungos leveduriformes do gênero Cândida.

\section{MATERIAL E MÉTODOS}

\section{Obtenção do material botânico}

Foram utilizadas as partes aéreas (folhas e caule) da planta, as quais foram coletadas no horto medicinal do LTF (Laboratório de Tecnologia Farmacêutica) da UFPB. A coleta foi realizada no início da floração, com a presença de brotos florais no dia 20 do mês de setembro de 2005. A identificação da planta foi feita por M.B. Costa e Silva em abril de 2002 (Exsicata IPA No 59725).

\section{Preparação do extrato, alcoolatura e óleo essencial}

O extrato hidroalcoólico foi preparado por maceração a temperatura ambiente das folhas dessecadas com álcool etílico a $90 \%$. O extrato foi filtrado e concentrado em rotaevapor até obter-se 54,5 g do resíduo do extrato bruto para realização dos testes. Para o preparo da alcoolatura (AA) foi utilizado $1 \mathrm{~kg}$ do caule da planta, macerado em 1 L de álcool etílico a 95\% em um recipiente fechado em temperatura ambiente durante três dias. Em seguida foi obtido um extrato fluido.

Óleo essencial (OE) foi obtido a partir de $1,8 \mathrm{~kg}$ das folhas de $K$. brasiliensis através de hidrodestilação em aparelho de Clevenger, obtendo-se $0,4 \mathrm{~mL}$. O óleo foi acondicionado em frasco âmbar fechado hermeticamente e mantidos a temperatura de $4{ }^{\circ} \mathrm{C}$ até a realização dos experimentos (Cunha, 2004).

\section{Microrganismos}

Foi utilizado um total de 22 microrganismos incluindo bactérias gram-positivas de Staphylococcus aureus caracterizadas como sensíveis (MSSA) e resistentes a meticilina (MRSA) (Freitas, 1992). Linhagens de Streptococcus mitis, Streptococcus mutans, Streptococcus sanguis, Streptococcus sobrinus, Lactobacilos casei e bactérias gram-negativas como Pseudomonas aeruginosa ATCC 15442, Escherichia coli ATCC 25922, Salmonela typhi ATCC 114028, Micrococcus luteus e fungos leveduriformes do gênero Cândida, incluindo as espécies C. albicans ATCC 76645, C. tropicalis FCF-163, C. parapsilis LM-10, Candida krusei 19, C. stellatoidea, C. guilliamondi LM-06. Os microrganismos testados foram obtidos de pacientes internados no Hospital Universitário Lauro Wanderley/UFPB. As linhagens ATCC 25923 e ATCC 65398 foram utilizadas como amostras de referência nos experimentos realizados com amostras gram-positivas (National, 1988). A linhagem ATCC 76645 de Candida albicans foi usada como referência nos ensaios antifúngicos. As gram-negativas utilizadas foram todas amostras padrão.

\section{Atividade antimicrobiana (Determinação da CIM)}

A atividade antimicrobiana em placas foi determinada pelo método de difusão em meio sólido para a determinação da Concentração Inibitória Mínima (CIM) do extrato, alcoolatura e o óleo essencial de Kalanchoe brasiliensis Cambess. Os microrganismos foram cultivados em caldo nutritivo (BHI - Brain Heart InfusionDIFCO) e incubados a $37^{\circ} \mathrm{C}$ por $18-20 \mathrm{~h}$. Diluíram-se 0,1 $\mu \mathrm{L}$ do inóculo em $10 \mathrm{~mL}$ de salina $\left(10^{-1}\right)$, tal diluição foi derramada nas placas sendo estas postas para secarem entreabertas na estufa a $37{ }^{\circ} \mathrm{C}$ por aproximadamente 30 min. Após a retirada das placas, foram feitas perfurações no meio de cultura (Agar Müeller Hinton - DIFCO) de aproximadamente $6 \mathrm{~mm}$ de diâmetro com ponteiras estéreis. Nos orifícios foi colocado um volume de $50 \mu \mathrm{L}$ da concentração mãe do extrato e alcoolatura variando na diluição de 1:1 a 1:1024 (National, 1988). As soluções do óleo essencial foram de 8,0, 4,0, 2,0, 1,0, 0,5 e 0,25\% (Allegrini et al., 1973). As placas foram incubadas a 37 ${ }^{\circ} \mathrm{C}$ por um período de $24 \mathrm{~h}$ para as cepas bacterianas, e $48 \mathrm{~h}$ para as amostras de fungos. Foi considerada como CIM a menor concentração da substância que inibiu o crescimento do microrganismo, observado pela presença do halo de inibição. O resultado foi considerado positivo quando o produto testado apresentou halo de inibição $\leq \mathrm{a}$ $10 \mathrm{~mm}$ de diâmetro. As drogas padrões utilizadas foram o antibiótico Norfloxacina $(10 \mu \mathrm{g})$ Laborclin e o antifúngico Cetoconazol para fungos. Como controle negativo o álcool etanol $(70 \%)$. 


\section{Cinética bactericida}

A curva bactericida foi avaliada pelo método de Peyret et al., (1990). A amostra selecionada foi cultivada em caldo nutritivo (Brain Heart Infusion - DIFCO) por 18$24 \mathrm{~h}$ a $370 \mathrm{C}$, e subcultivadas em caldo Müeller Hinton (DIFCO). O volume de $1 \mathrm{~mL}$ dos produtos testados foi adicionado a $9 \mathrm{~mL}$ do subcultivo - tubo tratado; e ao tubo controle $1 \mathrm{~mL}$ de água esterilizada a $9 \mathrm{~mL}$ do subcultivo. Em seguida os tubos foram mantidos na estufa a $370 \mathrm{C}$ e a cada $2 \mathrm{~h}$ foram retiradas alíquotas de $100 \mu \mathrm{L}$ das diluições dos tubos controle e tratados, em seguida semeadas em Agar Müeller Hinton - DIFCO. A leitura das placas foi efetuada pelo método padrão de contagem em placas, após $24 \mathrm{~h}$ de incubação. O tempo de morte das bactérias foi expresso em $\log _{10}$.

\section{RESULTADOS}

O resultado da atividade antimicrobiana demonstrou que o extrato hidroalcoólico inibiu apenas duas amostras, porém, o óleo essencial de K. brasiliensis apresentou atividade em um número maior de amostras, sendo por este motivo o escolhido para a cinética bactericida.
Tal atividade foi observada em amostras gram-positivas de S. aureus, incluindo amostras multiresistentes e sensíveis a meticilina, e o diâmetro dos halos variaram de 10 a $17 \mathrm{~mm}$, determinando dessa forma, a CIM do óleo essencial nas amostras sensíveis ao mesmo como apresentado na Tabela 1 e Figura 3. As amostras dos gêneros Streptococcus e Candida e as bactérias gram-negativas, nenhuma se mostrou sensível às substâncias testadas.

No ensaio da curva bactericida foi avaliado o óleo essencial sobre a amostra de $S$. aureus 10cc (MRSA) nas concentrações de $1 \%$, correspondente a sua CIM e na concentração de $4 \%$, duas vezes sua CIM. Frente à amostra padrão ATCC 6538 (MRSA) foi avaliada a concentração de $8 \%$. As curvas podem ser visualizadas nas Figuras 1 e 2 , respectivamente.

A menor concentração do $\mathrm{OE}$ de $K$. brasiliensis não inibiu a amostra, apresentando uma curva de crescimento eqüitativo a curva controle. Na concentração de $4 \%$ o início da inibição ocorreu a partir da sexta hora de exposição ao óleo essencial com uma diminuição de um $\log _{10}$ em UFC/mL, semelhante ao comportamento da amostra padrão ATCC 6538 tratada na maior concentração (8\%). Porém nesta concentração, o óleo essencial inibiu em até $24 \mathrm{~h}$ o crescimento bacteriano (Figura 1).

Tabela 1. Determinação da CIM (Concentração Inibitória Mínima) do extrato hidroalcoólico e Óleo essencial das folhas, e da alcoolatura do caule de Kalanchoe brasiliensis frente a amostras bacterianas gram-positivas e gram-negativas.

\begin{tabular}{|c|c|c|c|c|c|c|c|c|c|c|c|}
\hline \multirow{3}{*}{ Amostras Bacterianas } & \multicolumn{11}{|c|}{$\begin{array}{c}\text { Inibição de kalanchoe brasiliensis Cambess } \\
\text { Zona de inibição diâmetro (mm) } \\
\text { Concentração das substâncias }(\mathrm{mg} / \mathrm{mL})\end{array}$} \\
\hline & EHF & EHF & EHF & $\mathrm{AAC}$ & $\mathrm{OE}$ & $\mathrm{OE}$ & $\mathrm{OE}$ & $\mathrm{OE}$ & $\mathrm{OE}$ & $\mathrm{OE}$ & Nor \\
\hline & 1000 & 500 & 10 & 1000 & $8 \%$ & $4 \%$ & $2 \%$ & $1 \%$ & $0,5 \%$ & $0,25 \%$ & $10 \mu \mathrm{g}$ \\
\hline *S.aureus ATCC 65398 & 11 & - & - & - & 11 & 10 & 10 & - & - & - & 22 \\
\hline *S.aureus $02 \mathrm{Hu}$ & - & - & - & - & 11 & 10 & - & - & - & - & 23 \\
\hline *S.aureus $06 \mathrm{cc}$ & - & - & - & - & 12 & 11 & 10 & - & - & - & - \\
\hline *S.aureus $09 \mathrm{cc}$ & - & - & - & - & 11 & 10 & - & - & - & - & 25 \\
\hline *S.aureus $10 \mathrm{cc}$ & - & - & - & - & 13 & 12 & 11 & 10 & - & - & 24 \\
\hline *S.aureus 19 lab & - & - & - & - & 15 & 15 & 14 & 13 & 11 & 10 & - \\
\hline *S.aureus 119 lab & - & - & - & - & 11 & 10 & 10 & - & - & - & 27 \\
\hline *S.aureus 149 lab & - & - & - & - & 12 & 11 & 10 & - & - & - & 26 \\
\hline *S.aureus $171 \mathrm{cc}$ & - & - & - & - & 17 & 13 & 10 & - & - & - & 24 \\
\hline *S.aureus 259 I & 11 & - & - & - & 12 & 11 & - & - & - & - & 25 \\
\hline **S.aureus ATCC 25923 & - & - & - & - & 11 & 11 & - & - & - & - & - \\
\hline **S.aureus $05 \mathrm{cc}$ & - & - & - & - & 11 & 10 & 10 & - & - & - & 26 \\
\hline **S.aureus $173 \mathrm{I}$ & - & - & - & - & - & - & - & - & - & - & $\mathrm{N}$ \\
\hline Streptococcus mitis & - & - & - & - & - & - & - & - & - & - & $\mathrm{N}$ \\
\hline Streptococcus mutans & - & - & - & - & - & - & - & - & - & - & $\mathrm{N}$ \\
\hline Streptococcus sanguis & - & - & - & - & - & - & - & - & - & - & $\mathrm{N}$ \\
\hline Streptococcus sobrinos & - & - & - & - & - & - & - & - & - & - & $\mathrm{N}$ \\
\hline Lactobacilos casei & - & - & - & - & - & - & - & - & - & - & $\mathrm{N}$ \\
\hline *** Micrococcus luteus & - & - & - & - & - & - & - & - & - & - & 20 \\
\hline $\begin{array}{l}* * * \text { Salmonela typhi } \\
\text { ATCC } 14028\end{array}$ & - & - & - & - & - & - & - & - & - & - & 21 \\
\hline $\begin{array}{l}\text { ***Pseudomonas } \\
\text { aeruginosa ATCC } 15442\end{array}$ & - & - & - & - & - & - & - & - & - & - & 23 \\
\hline
\end{tabular}


Curva bacteriostática do Óleo es sencial de Kbrasiliensis frente amos tra (10 cc) MRSA de Staphylococus aureus

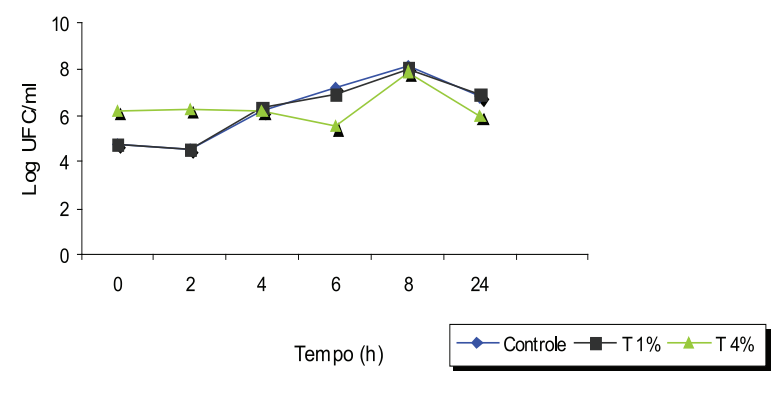

Figura 1. Representação da Curva de crescimento da amostra de Staphylococcus aureus 10 cc (MRSA) tratada com o óleo essencial das folhas de Kalanchoe brasiliensis Cambess a $1 \%$ (CIM) e na concentração 4\% (2x CIM).

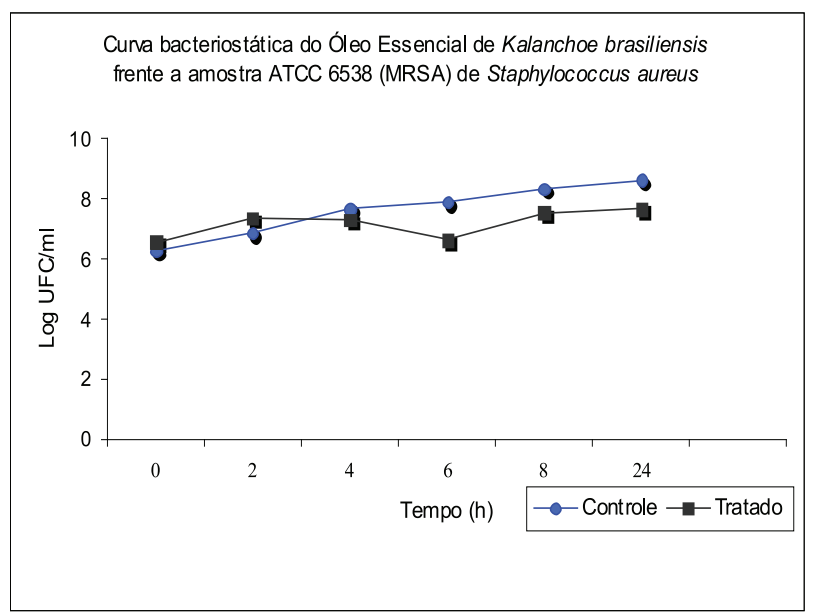

Figura 2. Representação da Curva de crescimento da amostra de Staphylococcus aureus ATCC 6538 (MRSA) tratada com o óleo essencial das folhas de Kalanchoe brasiliensis Cambess na concentração de $8 \%$ (2x CIM)

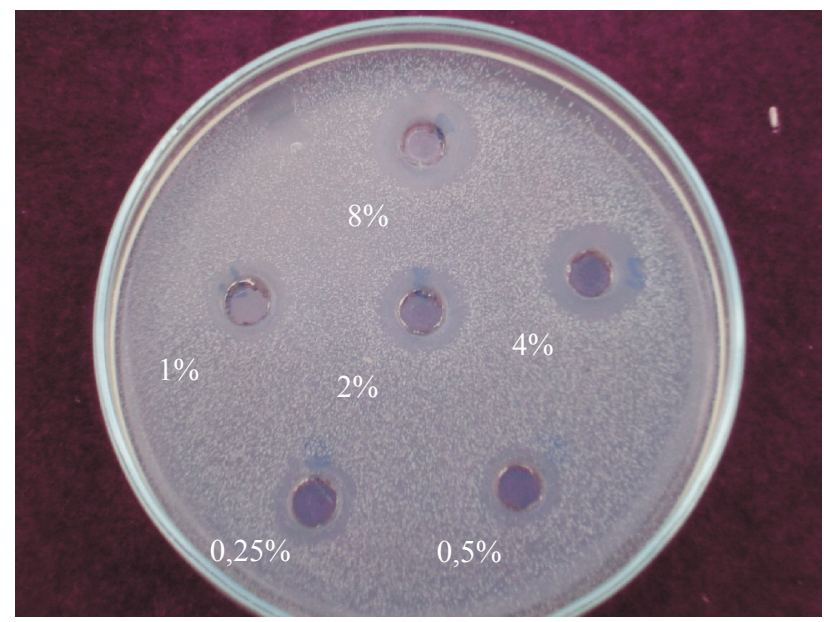

Figura 3. Representação dos halos de inibição sobre a amostra 19L (MRSA) de Staphylococcus aureus tratada com óleo essencial das folhas de Kalanchoe brasiliensis Cambess.

\section{DISCUSSÃO}

O interesse em estudos de plantas medicinais com atividade antimicrobiana vem crescendo por dois motivos: primeiro por simbolizar muitas vezes o único recurso terapêutico de muitas comunidades (Pinto et al., 2002; Souza et al., 2003) e segundo, devido às opções para terapias antimicrobianas terem diminuído, motivo este inerente à resistência adquirida naturalmente pelas bactérias, ou pelo uso indiscriminado de drogas que aumenta largamente o número de cepas resistentes, tornando a multiresistência preocupante e o futuro de drogas antimicrobianas incerto (May et al., 2000).

A qualidade anti-séptica de óleos essenciais é geralmente devida a grande mistura de constituintes como terpenóides e hidrocarbonos (ácido, álcool, aldeídos), dos quais fizeram fluir grande interesse na comunidade científica com investigações frente a diferentes microrganismos (Dorman \& Deans, 2000).

Segundo relatado por Dorman \& Deans (2000), compostos fenólicos pode apresentar atividade bacteriostática ou bactericida dependendo da sua concentração, e de acordo com Nascimento et al., (2000) estes compostos estão presentes em óleos essenciais. Em estudo prévio de avaliação fitoquímica por Stevens et al. (1995) foi revelada a presença de taninos condensados no gênero de Kalanchoe brasiliensis, além da presença de flavonóides constatada por Costa et al., (1994), podendo estes efeitos observados no presente estudo serem devido à presença dos mesmos.

O efeito bacteriostático aqui demonstrado é relevante quando comparado à ação de uma nova classe de antibióticos, oxalinezolida e seu antibiótico avaliado AZD, o qual apresentou efeito bacteriostático frente a amostras de $S$. aureus, em que Jones et al. (2002) consideraram atividade bacteriostática quando houve redução de até dois $\log _{10} \mathrm{CFU} / \mathrm{ml}$ comparado ao inóculo inicial, resultado semelhante ao o observado pelo $\mathrm{OE}$ nas amostras multiresistentes de $S$. aureus, aqui avaliadas.

Vale ressaltar que, a CIM apresentada variou entre as amostras devido ao diferente perfil de resistência nelas presente, e que o aumento no crescimento bacteriano nas concentrações $4 \%$ e $8 \%$ durante as duas primeiras horas de exposição da amostra ao óleo essencial, pode dever-se ao fato que o inóculo inicial para as mesmas foi maior na curva do tratado, em comparação ao o usado no controle.

O OE de $K$. brasiliensis não ter sido efetivo contra amostras gram-negativas, pode ser em razão da diferente composição bioquímica na estrutura celular dessas bactérias em comparação as gram-positivas, assim como descrito por Tortora (2000), discordando com a proposição de Deans \& Ritchie (1987) quando ressaltam que a ação antibacteriana de óleos essenciais independe da reação de Gram (Dorman \& Deans, 2000). A ação negativa sobre as amostras de fungos corrobora com o estudo de Akinpelu (2000) em avaliação da Kalanchoe pinnata, espécie 
pertencente ao mesmo gênero da planta aqui estudada, e com o estudo de Cunha et al., (1995) ao demonstrar que o extrato de $K$. brasiliensis formou um halo de inibição frente a amostras de fungos, inferior ao aqui considerado como efetivo.

Os resultados descritos são muito interessantes pelo fato das amostras aqui testadas terem sido isoladas de ambiente hospitalar, onde há um difícil controle para infecções bacterianas principalmente as causadas por cepas multiresistentes.

\section{REFERÊNCIAS BIBLIOGRÁFICAS}

Akinpelu DA 2000. Antimicrobial activity of Bryophyllum pinnatum leaves. Fitoterapia 71: 193-194.

Allegrini J, Bouchberg MS, Mailols H 1973. Emulsions d'huiles essentielles fabrication et applications en microbiologie. Societé de Pharmacie de Montpellier 33: 73-86.

Costa SS, Jossang A, Bodo B 1994. Patuletin acetylrhamnosides from Kalanchoe brasiliensis as inhibitors of human lymmphocyte proliferative activity. J Nat Prod 57: 15031510.

Costa SS, Souza MLM, IbrahimT, Melo GO, Almeida AP, Guette C, Férézou JP, Koatz VL 2006. kalanchosine dimalate, an anti-inflamatory salt from Kalanchoe brasiliensis. J Nat Prod 69: 815-818.

Cowan MM 1999. Plants products as antimicrobial agents. Clin Microbiol Rev 12: 564-582.

Cunha RM 2004. Efeitos do óleo essencial de Ocotea ducka Valtino (Lauraceae) sobre parâmetros cardiovasculares de ratos. João Pessoa. 106p, Tese Doutorado, Universidade Federal da Paraíba.

Cunha GMA, Maia AAB, Néri DR, Nogueira NAP, Matos FJA 1995. Atividade antimicrobiana de plantas popularmente usadas no Ceará. Rev Bras Farm 76: 5-6.

Deans SG, Ritchie G 1987. Antibacterial properties of pant essential oils. Int J Food Microbiol 5: 165-180.

Dorman HJD, Deans SG 2000. Antimicrobial agents from plants: antibacterial activity of plant volatile oils. $J$ Appl Microbiol 88: 306-316.

Freitas FIS 1992. Caracterização fenotípica de amostras hospitalares de Staphylococcus aureus isoladas no Estado da Paraíba. João Pessoa. 70pp. Dissertação de Mestrado, Universidade Federal da Paraíba.

Ibrahim T, Cunha JMT, Madi T, Fonseca LMB, Costa SS, Koatz VLG 2002. Immunomodulatory and anti-inflammatory effects of Kalanchoe brasiliensis. J Ethnopharmacol 2: 875-883.

Ito T, Okuma K, Ma XX, Yuzawa H, Hiramatsu K 2003. Insights on antibiotic resistence of Staphylococcus aureus from its whole genome: genomic island SCC. Drug Resist Update 6: 41-52.

Jones RN, Anderegg TR, Despande LM 2002. AZD2563, a new oxazolidionone: bacterial activity and synergy studies combined with gentamicin or vancomycin angaist staphylococci and streptococcal strains. Diagn Micr
Infec Dis 43: 87-90.

May J, Chan C H, King A, Willians L, French GL 2000. Time Kill studies of tea tree oils on clinical isolates. J Antim Chemother 45: 639-643.

Mourão RHV, Santos FO, Franzotti EM, Moreno MPN, Antoniolli AR 1999. Antiinflamatory activity and acute toxicity $\left(\mathrm{LD}_{50}\right)$ of the juice of Kalanchoe brasiliensis (Comb.) leaves picked before and during blooming. Phytother Res 13: 352-354.

Nascimento GGF, Locatelli J, Freitas PC, Silva GL 2000. Antibacterial activity of extracts and phytochemicals antibiotic-resistant bacteria. Braz J Microbiol 31: 247256.

National CCLS 1988. Methods for diluition antimicrobial susceptibility test for bacteria that grow aerobically. Tentative Standart Document M7 - T2, 8.

Peyret M, Carret G, Carre C, Fardel G, Flandrois JP 1990. Mathematical study of the sensitivity curves of Escherichia coli exposed to polymyxins. Pathol Biol 38: 441-445.

Pinto AC, Silva DHS, Bolzani VS, Lopes NP, Epifanio RA 2002. Produtos naturais: atualidades, desafios e perspectivas. Quim Nova 25: 45-61.

Souza GC, Haas APS, Poser Von GL, Schapoval EES, Elisabtsky E 2003. Ethnopharmacology studies of antimicrobial remedies in the South Brazil. J Ethnopharmacol 90: 135143.

Stevens JF, Hart HT, Roeland CHJ, Van H, Elema ET, Den Ent MMVX. Wildeboer M, Zwaving JH 1995. Distribution of alkaloids and tannins in the Crassulaceae. Biochem Systemat Ecology 23:157-165.

Stratton MDCW 2000. Nuances in antimicrobial susceptibility testing for resistant Gram-positive organisms. Antimicrobol Infec Dis New 18: 57-64.

Tortora GJ, Funke BR, Case CL 2000. Microbiologia. 6 ed. Porto Alegre: Artmed.

Trevisan TMS, Bezerra MZB, Santiago GMP, Feitosa CMF, Verpoort R, Brás-Filho R, 2006. Atividades larvicida e anticolinesterásica de plantas de gênero Kalanchoe. Quim Nova 29: 415-418.

Veiga Jr VFV, Pinto AC, Maciel MAM 2005. Plantas medicinais: Cura segura? Quim Nova 28: 519-528. 